\title{
Vaccine effectiveness against severe acute respiratory infections (SARI) COVID-19 hospitalisations estimated from real-world surveillance data, Slovenia, October 2021
}

Marta Grgič Vitek ${ }^{1}$, Irena Klavss ${ }^{1}$, Veronika Učakar ${ }^{1}$, Mojca Serdt' ${ }^{1}$, Maja Mrzel ${ }^{1}$, Marjana Vrh ${ }^{1}$, Mario Fafangel ${ }^{1}$

1. Communicable Diseases Centre, National Institute of Public Health, Ljubljana, Slovenia

Correspondence: Marta Grgič Vitek (marta.vitek@nijz.si)

Citation style for this article:

Grgič Vitek Marta, Klavs Irena, Učakar Veronika, Serdt Mojca, Mrzel Maja, Vrh Marjana, Fafangel Mario. Vaccine effectiveness against severe acute respiratory infections (SARI) COVID-19 hospitalisations estimated from real-world surveillance data, Slovenia, October 2021. Euro Surveill. 2022;27(1):pii=2101110. https:// doi.org/10.2807/1560-7917.ES.2022.27.1.2101110

Article submitted on 3 Dec 2021 / accepted on 17 Dec 2021 / published on 06 Jan 2022

We estimated vaccine effectiveness (VE) against severe COVID-19 during October 2021, using Slovenian surveillance data. For people fully vaccinated with any vaccine in age groups $18-49,50-64, \geq 65$ years, VE was $86 \%$ (95\% Cl: $79-90), 89 \%(85-91)$, and $77 \%(74-$ $81)$. Among $\geq 65$ year-olds fully vaccinated with mRNA vaccines, VE decreased from $93 \%$ (95\% Cl: $88-96)$ in those vaccinated $\leq 3$ months ago to $43 \%(95 \% \mathrm{Cl}$ : $30-54$ ) in those vaccinated $\geq 6$ months ago, suggesting the need for early boosters.

To inform vaccination strategy it is important to understand the effectiveness of vaccination against severe coronavirus disease (COVID-19). In Slovenia, by the end of September 2021, the vaccination coverage against COVID-19 was rather low (47.2\% among $18-49$ year-olds, $63.5 \%$ among $50-64$ year-olds, and $76.1 \%$ among $\geq 65$ year-olds) and waning immunity may have occurred, especially among elderly people ( $\geq 65$ yearolds) who were vaccinated first [1]. Here we estimated vaccine effectiveness (VE) against hospitalisation due to severe acute respiratory infection (SARI) COVID19 during October 2021 (weeks 39 to 43; from 27 September to 31 October), when the severe acute respiratory syndrome coronavirus 2 (SARS-CoV-2) Delta variant was predominant, by age groups, for all vaccines used and separately for mRNA vaccines and viral vector vaccines. Additionally, we estimated VE against hospitalisation due to SARI COVID-19 for mRNA vaccines by time since vaccination.

We used comprehensive national COVID-19 surveillance data and data on vaccination against COVID19 collected at the National Institute of Public Health (Nacionalni inštitut za javno zdravje (NIJZ)).
Case definitions and other definitions

A SARI COVID-19 case was defined as an individual with SARI and a positive SARS-CoV-2 reverse transcription PCR (RT-PCR) or antigen test result at admission to hospital [2]. A case with a previous COVID-19 diagnosis was defined as an individual with a record of a positive SARS-CoV-2 RT-PCR in the national COVID-19 database more than 3 weeks before the week under observation. Fully vaccinated individuals were those who completed the primary recommended vaccination schedule with any vaccine used in Slovenia: Comirnaty (BNT162b2 mRNA, BioNTech-Pfizer, Mainz, Germany/ New York, United States) or Spikevax (mRNA-1273, Moderna, Cambridge, United States) or Vaxzervia (ChAdOx1 nCoV-19, Oxford-AstraZeneca, Cambridge, United Kingdom) or Janssen vaccine (Ad26.COV2-S, Janssen-Cilag International NV, Beerse, Belgium) at least 14 days before the week under observation in the national EPISARI surveillance database. Unvaccinated individuals were defined as individuals who had not received any dose of vaccine against COVID-19.

\section{Data sources}

Three different sources were used in the analysis: (i) weekly numbers of SARI COVID-19 cases admitted to hospitals were extracted from EPISARI [2], (ii) vaccination status of all individuals vaccinated in Slovenia was obtained from the national Electronic registry of vaccinated individuals and adverse events following immunisation (eRCO) [3] and (iii) previous diagnosis of COVID-19 was retrieved from the national COVID19 database. By using unique national identifiers, we were able to link the data from the three databases to ascertain the vaccination status of SARI COVID-19 cases admitted to hospitals and previous diagnosis of COVID-19 among fully vaccinated individuals. 
Vaccine effectiveness for all vaccine types, mRNA vaccines and viral vector vaccines, against hospitalisation due to SARI COVID-19, by age group, Slovenia, October 2021

\begin{tabular}{|c|c|c|c|c|c|c|}
\hline \multirow{2}{*}{ Age group (years) } & \multicolumn{2}{|c|}{$\begin{array}{l}\text { Fully vaccinated individuals without previous } \\
\qquad \text { COVID-19 } 9^{\mathrm{a}, \mathrm{b}}\end{array}$} & \multicolumn{2}{|c|}{$\begin{array}{l}\text { Unvaccinated individuals without previous } \\
\text { COVID }-19^{\mathrm{a}, \mathrm{c}}\end{array}$} & \multicolumn{2}{|c|}{ Vaccine effectiveness } \\
\hline & 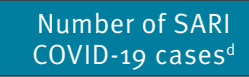 & $\begin{array}{l}\text { Rate per } 100,000 \\
\text { population }\end{array}$ & 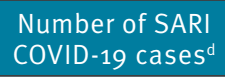 & $\begin{array}{l}\text { Rate per } 100,000 \\
\text { population }\end{array}$ & $\%$ & $95 \% \mathrm{Cl}$ \\
\hline \multicolumn{7}{|l|}{ All vaccines } \\
\hline $18-49$ & 27 & 8.0 & 179 & 55.8 & 86 & $79-90$ \\
\hline $50-64$ & 63 & 25.7 & 270 & 229.9 & 89 & $85-91$ \\
\hline$\geq 65$ & 281 & 99.2 & 383 & 438.2 & 77 & $74-81$ \\
\hline \multicolumn{7}{|l|}{ mRNA vaccines } \\
\hline $18-49$ & 8 & 4.2 & 179 & 55.8 & 92 & $85-96$ \\
\hline $50-64$ & 23 & 15.4 & 270 & 229.9 & 93 & $90-96$ \\
\hline$\geq 65$ & 243 & 93.1 & 383 & 438.2 & 79 & $75-82$ \\
\hline \multicolumn{7}{|c|}{ Viral vector vaccines } \\
\hline $18-49$ & 19 & 13.2 & 179 & 55.8 & 76 & $62-85$ \\
\hline $50-64$ & 39 & 41.3 & 270 & 229.9 & 82 & $75-87$ \\
\hline$\geq 65$ & 36 & 169.2 & 383 & 438.2 & 61 & $46-73$ \\
\hline
\end{tabular}

CI: confidence interval; COVID-19: coronavirus disease; mRNA: messenger ribonucleic acid; SARI: severe acute respiratory infection; SARSCoV-2: severe acute respiratory syndrome coronavirus 2.

a Individuals without previous COVID-19 diagnosis were defined as individuals without a record of a positive SARS-CoV-2 RT-PCR in the national COVID-19 database more than 3 weeks before the week under observation within the SARI surveillance database known as EPISARI [2].

${ }^{b}$ Fully vaccinated individuals with any vaccine were defined as individuals who had received two doses of mRNA vaccines (Comirnaty (BNT162b2 mRNA, BioNTech-Pfizer, Mainz, Germany/New York, United States) or Spikevax (mRNA-1273, Moderna, Cambridge, United States)) or viral vector vaccine (Vaxzervia (ChAdOx1 nCoV-19, Oxford-AstraZeneca, Cambridge, United Kingdom)) or one dose of viral vector vaccine Janssen (Ad26.COV2-S, Janssen-Cilag International NV, Beerse, Belgium) at least 14 days before the week under observation. ' Unvaccinated individuals were defined as individuals who had not received any dose of vaccine against COVID-19.

' SARI COVID-19 cases were defined as all SARI cases testing positive for SARS-CoV-2 by PCR or antigen test at admission to hospitals.

Data sources: EPISARI surveillance of severe acute respiratory infections within comprehensive COVID-19 surveillance [2], national electronic registry of vaccinated individuals and adverse events following vaccinations (eRCO), national COVID-19 dataset and Slovenian Central Population Registry.

\section{Calculating vaccine effectiveness}

To estimate VE against hospitalisation due to SARI COVID-19 for all vaccines used in Slovenia and separately for mRNA and viral vector vaccines (by age groups and by time since vaccination), we used the respective rates of SARI COVID-19 cases in fully vaccinated individuals without previous diagnosis of COVID-19 and respective rates of SARI COVID-19 cases in unvaccinated individuals without previous diagnosis of COVID-19.

Vaccine effectiveness was calculated using the formula: $(1-R R) \times 100$, where $R R$ was the ratio of severe COVID-19 cases rate in the fully vaccinated, to the equivalent rate in the unvaccinated.

To obtain denominators for fully vaccinated individuals without previous diagnosis of COVID-19, the number of fully vaccinated individuals with previous COVID19 diagnosis was subtracted from the number of fully vaccinated individuals. To obtain estimates of denominators for unvaccinated individuals without previous diagnosis of COVID-19, we subtracted the number of individuals who have received at least one dose of any vaccine against COVID-19, and the number of individuals with previous COVID-19 diagnosis, from the total number of individuals in the Central Population Registry as of 1 of January 2021.

\section{Vaccine effectiveness against SARI COVID-19 hospitalisations}

During October 2021, VE for all vaccines as well as for mRNA and viral vector vaccines against SARI COVID-19 hospitalisations was lowest in the oldest age group (Table 1). Viral vector vaccines were less effective in preventing hospitalisations due to SARI COVID-19 in comparison to mRNA vaccines in all age groups.

Among individuals fully vaccinated with mRNA vaccines 6 months ago or longer, VE against hospitalisation due to SARS COVID-19 was substantially lower among those aged 65 years and older (43\%; 95\% Cl: 31-54\%) in comparison to those 50 to 64 years old (89\%; $95 \%$ Cl: 56-97\%) (Table 2).

\section{Ethical statement}

Ethical approval was not necessary because all surveillance data used are mandatorily collected according to the law.

\section{Discussion}

The effectiveness of COVID-19 vaccines has been recently intensively studied. Some reports suggested 
Vaccine effectiveness of mRNA vaccines against hospitalisation due to SARI COVID-19 by time since vaccination and age group, Slovenia, October 2021

\begin{tabular}{|c|c|c|c|c|c|c|}
\hline \multirow{2}{*}{ Age group (years) } & \multicolumn{2}{|c|}{$\begin{array}{l}\text { Fully vaccinated individuals without previous } \\
\qquad \text { COVID }-19^{a, b}\end{array}$} & \multicolumn{2}{|c|}{$\begin{array}{l}\text { Unvaccinated individuals without previous } \\
\qquad \text { COVID }-19^{\mathrm{a}, \mathrm{c}}\end{array}$} & \multicolumn{2}{|c|}{$\begin{array}{l}\text { Vaccine } \\
\text { effectiveness }\end{array}$} \\
\hline & 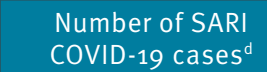 & $\begin{array}{l}\text { Rate per } 100,000 \\
\text { population }\end{array}$ & 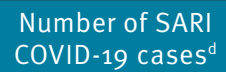 & $\begin{array}{l}\text { Rate per } 100,000 \\
\text { population }\end{array}$ & $\%$ & $95 \% \mathrm{Cl}$ \\
\hline \multicolumn{7}{|c|}{ Vaccinated $\leq 3$ months ago } \\
\hline $18-49$ & 3 & 1.7 & 179 & 55.8 & 97 & $90-99$ \\
\hline $50-64$ & 14 & 12.7 & 270 & 229.9 & 94 & $91-97$ \\
\hline$\geq 65$ & 17 & 31.3 & 383 & 438.2 & 93 & $88-96$ \\
\hline \multicolumn{7}{|c|}{ Vaccinated 4-5 months ago } \\
\hline $18-49$ & 0 & 0.0 & 179 & 55.8 & NA & NA \\
\hline $50-64$ & 7 & 22.8 & 270 & 229.9 & 90 & $79-95$ \\
\hline$\geq 65$ & 107 & 67.5 & 383 & 438.2 & 85 & $81-88$ \\
\hline \multicolumn{7}{|c|}{ Vaccinated $\geq 6$ months ago } \\
\hline $18-49$ & 5 & 42.8 & 179 & 55.8 & 23 & $0-69$ \\
\hline $50-64$ & 2 & 25.0 & 270 & 229.9 & 89 & $56-97$ \\
\hline$\geq 65$ & 119 & 248.3 & 383 & 438.2 & 43 & $30-54$ \\
\hline
\end{tabular}

$\mathrm{CI}$ : confidence interval; COVID-19: coronavirus disease; mRNA: messenger ribonucleic acid; NA: not applicable; SARI: severe acute respiratory infection; SARS: severe acute respiratory syndrome coronavirus 2.

a Individuals without previous COVID-19 diagnosis were defined as individuals without a record of a positive SARS-CoV-2 RT-PCR in the national COVID-19 database more than 3 weeks before the week under observation within the SARI surveillance database known as EPISARI [2].

${ }^{b}$ Fully vaccinated individuals with MRNA vaccines were defined as individuals who had received two doses of Comirnaty (BNT162b2 mRNA, BioNTech-Pfizer, Mainz, Germany/New York, United States) or Spikevax (mRNA-1273, Moderna, Cambridge, United States) vaccine at least 14 days before the week under observation.

' Unvaccinated individuals were defined as individuals who had not received any dose of vaccine against COVID-19.

d SARI COVID-19 cases were defined as all SARI cases testing positive for SARS-CoV-2 by PCR or antigen test at admission to hospitals.

Data sources: EPISARI surveillance of severe acute respiratory infections within comprehensive COVID-19 surveillance [2], national electronic registry of vaccinated individuals and adverse events following vaccinations (eRCO), national COVID-19 dataset and Slovenian Central Population Registry.

decreased VE against infection by the SARS-CoV-2 Delta variant [4], others indicated modest differences in VE against symptomatic disease with the Delta variant as compared with the Alpha variant [5], and some studies found maintained VE against hospitalisation due to severe disease [6-8]. Our results suggest that vaccines used in Slovenia were effective against hospitalisation due to SARI COVID-19 in fully vaccinated individuals during October 2021 when the Delta variant was predominant. The estimated VE was $86 \%$ (95\% Cl: 79-90), $89 \%$ (95\% Cl: 85-91), and $77 \%$ (95\% Cl: $74-81)$ among age groups $18-49,50-64$, and 65 years and older, for vaccination with any vaccine used in Slovenia. For mRNA vaccines the VE point percentage values showed an even greater risk reduction of SARI COVID-19 hospitalisation in all age groups, even though the $95 \%$ confidence intervals overlapped. Similar effectiveness of mRNA vaccines against hospitalisation due to severe COVID-19 was observed by others [6-9], and the European Centre for Disease Prevention and Control estimated the effectiveness of the Comirnaty vaccine against hospitalisation due to SARI-confirmed COVID19 during the pre-Delta period in elderly people $(\geq 65$ years) at $91 \%(95 \% \mathrm{Cl}: 80-96)$ [10].

The estimated VE against hospitalisation due to SARI COVID-19 in fully vaccinated Slovenian individuals during October 2021 for vector vaccines was statistically significantly lower compared with mRNA VE for all three age groups investigated here.

It is important to note that VE of mRNA vaccines against SARI COVID-19 hospitalisation decreased substantially with the increasing time since vaccination, especially in elderly people ( $\geq 65$ years) to only $43 \%(95 \% \mathrm{Cl}$ : $31-54 \%)$ for those fully vaccinated 6 months ago or more. This finding suggested that more than half of the elderly people fully vaccinated 6 months or more ago were no longer sufficiently protected against hospitalisation due to severe COVID-19. Waning immunity has also been reported by others [11-13]. Thus, our results provide additional evidence of substantially declining protection with time since vaccination against hospitalisation due to severe COVID-19 in elderly people and the need for a timely booster dose, especially in this age group.

The strength of our study is in the real-world national surveillance data collected from all Slovenian hospitals (EPISARI), and data from official national registries (eRCO and COVID-19 database). Surveillance of SARI COVID-19 cases within EPISARI has some limitations, however, which have been described in detail elsewhere [2]. In brief, the data collection process is at the 
discretion of the individual hospital and there may be variation in case ascertainment [2]. Some SARI cases and COVID-19 cases may have been misclassified or under-reported [2]. As previous infection with SARSCoV-2 may confer protection for some time, it was important to exclude prior COVID-19 confirmed cases from analysis to not underestimate VE [14]. It should be noted that the likelihood of systematic unmeasured differences between vaccinated and unvaccinated individuals (e.g. adherence to non-pharmaceutical measures) could influence the rates of COVID-19 in the two groups. Also, comparison of VE between different age groups may be affected by differences in the overall time after full vaccination in different age groups. As at 31 October 2021, the average time elapsed since being fully vaccinated was 110 days for 18-49 year-olds, 131 days for 50-64 year-olds and 172 days for those aged 65 years and older. Finally, as no information on comorbidities of SARI COVID-19 cases was available it was difficult to assess to what extent the reduced VE among individuals immunised at the beginning of the pandemic occurred because individuals at high risk of severe disease were prioritised for early vaccination. For example, in the age group 18-49 years old, among five SARI COVID-19 cases fully vaccinated 6 months ago or longer, we were able to obtain information on comorbidities associated with high risk for severe COVID-19 for four individuals. Nevertheless, we believe that our real-world national VE data are robust enough to inform our vaccination strategies.

\section{Conclusion}

Our results show that vaccines used in Slovenia were highly effective against hospitalisation due to SARI COVID-19 in fully vaccinated individuals up to 6 months after completed vaccination during the period of predominant Delta variant circulation. Six months or longer after completed vaccination, protection decreased substantially for those aged 65 years and older. It is thus important that individuals belonging to this group receive a booster dose as soon as possible at an interval of 6 months or even earlier after primary vaccination to prevent a substantial proportion of hospitalisations due to SARI COVID-19. We plan to assess changes in VE for mRNA vaccines currently used in the near future, when the Omicron variant will have become predominant in our country.

\section{Acknowledgements}

We would like to thank the EPISARI Network members from the National Institute of Public Health and all 29 Slovenian hospitals for EPISARI data collection and management, and all vaccination teams in Slovenia to report vaccination data to eRCO.

\section{Funding statement}

Collecting of surveillance data is funded by the Slovenian Ministry of Health within the annual funding for the national programme implemented by the National Institute of Public Health (contract number C2711-21-708403).
Conflict of interest

None declared.

Authors' contributions

Marta Grgič-Vitek, Irena Klavs, Veronika Učakar and Mario Fafangel designed the study, and planned analyses in collaboration with Mojca Serdt, Maja Mrzel and Marjana Vrh. Maja Mrzel and Marjana Vrh analysed the data. Marta Grgič Vitek prepared the first draft of the manuscript in collaboration with Irena Klavs, Veronika Učakar, and Mario Fafangel. All authors revised the manuscript, read and approved the final manuscript.

\section{References}

1. National institute of Public Health (NIJZ). Cepljenje proti COVID-19 v Sloveniji. [Vaccination against COVID-19 in Slovenia]. Ljubljana: NIJZ. [Accessed: 2 Dec 2021]. Slovenian. Available from: https://app.powerbi.com/view? r=eyJrljoiYWQ3NGE1NTMtZWJkMiooNzZmLWFiNDItZDC5YjU5MGRkOGMyli

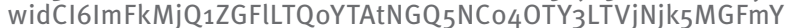
TQ2MylsImMiOjlg

2. Klavs I, Serdt M, Učakar V, Grgič-Vitek M, Fafangel M, Mrzel M, et al. Enhanced national surveillance of severe acute respiratory infections (SARI) within COVID-19 surveillance, Slovenia, weeks 13 to 37 2021. Euro Surveill. 2021;26(42):2100937. https://doi.org/10.2807/1560-7917.ES.2021.26.42.2100937 PMID: 34676822

3. National institute of Public Health (NIJZ). Elektronski register cepljenih oseb in neželenih učinkov po cepljenju. [Electronic Registry of vaccinated individuals and adverse events following vaccinations]. Ljubljana: NIJZ. [Accessed: 2 Dec 2021]. Slovenian. Available from: https://www.nijz.si/sl/elektronskiregister-cepljenih-oseb-in-nezelenih-ucinkov-po-cepljenju-erco

4. Seppälä E, Veneti L, Starrfelt J, Danielsen AS, Bragstad $\mathrm{K}$, Hungnes $\mathrm{O}$, et al. Vaccine effectiveness against infection with the Delta (B.1.617.2) variant, Norway, April to August 2021. Euro Surveill. 2021;26(35):2100793. https:// doi.org/10.2807/1560-7917.ES.2021.26.35.2100793 PMID: 34477054

5. Lopez Bernal J, Andrews N, Gower C, Gallagher E, Simmons R, Thelwall S, et al. Effectiveness of Covid-19 vaccines against the B.1.617.2 (Delta) variant. N Engl J Med. 2021;385(7):585-94. https://doi.org/10.1056/NEJMoa2108891 PMID: 34289274

6. Tenforde MW, Self WH, Naioti EA, Ginde AA, Douin DJ, Olson SM, et al. Sustained Effectiveness of Pfizer-BioNTech and Moderna Vaccines Against COVID-19 Associated Hospitalizations Among Adults - United States, March-July 2021. MMWR Morb Mortal Wkly Rep. 2021;70(34):1156-62. https://doi.org/10.15585/mmwr.mm7034e2 PMID: 34437524

7. Harder T, Külper-Schiek W, Reda S, Treskova-Schwarzbach M, Koch J, Vygen-Bonnet S, et al. Effectiveness of COVID-19 vaccines against SARS-CoV-2 infection with the Delta (B.1.617.2) variant: second interim results of a living systematic review and meta-analysis, 1 January to 25 August 2021. Euro Surveill. 2021;26(41):2100920. https://doi.org/10.2807/1560-7917. ES.2021.26.41.2100920 PMID: 34651577

8. Puranik A, Lenehan PJ, Silvert E, Niesen MJ, Corchado-Garcia J, O'Horo JC, et al. Comparison of two highly-effective mRNA vaccines for COVID-19 during periods of Alpha and Delta variant prevalence. medRxiv. 2021:2021.08.06.21261707v3. https:// doi.org/10.1101/2021.08.06.21261707

9. Thompson MG, Stenehjem E, Grannis S, Ball SW, Naleway AL, Ong TC, et al. Effectiveness of Covid-19 Vaccines in Ambulatory and Inpatient Care Settings. N Engl J Med. 2021;385(15):135571. https://doi.org/10.1056/NEJMoa2110362 PMID: 34496194

10. European Centre for Disease Prevention and Control (ECDC). Interim analysis of COVID-19 vaccine effectiveness against Severe Acute Respiratory Infection due to laboratory-confirmed SARS-CoV-2 among individuals aged 65 years and older, ECDC multi-country study. Stockholm: ECDC; 8 Oct 2021. Available from: https://www.ecdc.europa.eu/en/publications-data/interim-analysis-covid-19-vaccine-effectiveness-against-severeacute-respiratory

11. Israel A, Merzon E, Schäffer AA, Shenhar Y, Green I, GolanCohen A, et al. Elapsed time since BNT162b2 vaccine and risk of SARS-CoV-2 infection: test negative design study. BMJ. 2021;375:eo67873. https://doi.org/10.1136/bmj-2021-067873 PMID: 34819275 
12. Chemaitelly H, Tang P, Hasan MR, AlMukdad S, Yassine $\mathrm{HM}$, Benslimane FM, et al. Waning of BNT162 b2 Vaccine Protection against SARS-CoV-2 Infection in Qatar. N Engl J Med. 2021:NEJMoa2114114.

13. Goldberg Y, Mandel M, Bar-On YM, Bodenheimer O, Freedman L, Haas EJ, et al. Waning Immunity after the BNT162 b2 Vaccine in Israel. N Engl J Med. 2021:NEJMoa2114228.

14. Havervall S, Ng H, Jernbom Falk A, Greilert-Norin N, Månberg $A$, Marking $U$, et al. Robust humoral and cellular immune responses and low risk for reinfection at least 8 months following asymptomatic to mild COVID-19. J Intern Med. 2021;joim.13387.; Epub ahead of print. PMID: 34459525

\section{License, supplementary material and copyright}

This is an open-access article distributed under the terms of the Creative Commons Attribution (CC BY 4.0) Licence. You may share and adapt the material, but must give appropriate credit to the source, provide a link to the licence and indicate if changes were made.

Any supplementary material referenced in the article can be found in the online version.

This article is copyright of the authors or their affiliated institutions, 2022. 